eISSN: 2172-9077

https://doi.org/10.14201/fjc20191887101

\title{
EL WEBDOC COMO HERRAMIENTA EN LA LUCHA POR LA IGUALDAD: EN LA BRECHA (2018) DEL LAB RTVE
}

\section{The webdoc as a tool in the struggle for equality: En la brecha (2018) by Lab RTVE}

\author{
Dra. María Purificación SUBIRES MANCERA \\ Profesora e investigadora \\ Universidad de Málaga, España \\ E-mail: purificacion@uma.es \\ (iD) http://orcid.org/0000-0002-9566-1623
}

Fecha de recepción del artículo: 30/03/2019

Fecha de aceptación definitiva: 18/04/2019

\begin{abstract}
RESUMEN
El webdoc, como evolución interactiva y multimedia del documental cinematográfico y televisivo, y que nace con el desarrollo de Internet, mantiene la misma esencia de sus precedentes: su carácter informativo y de denuncia y su visión crítica de la realidad. En este trabajo se analiza, utilizando como metodología el estudio de caso, el webdoc En la brecha, del Lab de RTVE, elaborado con motivo de la celebración del Día Internacional por la Igualdad Salarial del año 2018, y a través del que se pretendía denunciar la brecha salarial -de ahí el título del webdoc- existente entre mujeres y hombres en el salario medio anual. A su vez, también aspiraba a visibilizar el trabajo de la mujer en aquellos sectores en los que está menos representada, por medio de la experiencia vital y el testimonio de siete mujeres, de diferentes profesiones. El proyecto no se limitaba a mostrar estos siete casos, sino que también ofrecía a otras mujeres la posibilidad de participar, aportando a través de la web sus propias vivencias y opiniones - grabadas por ellas mismas, con un móvil o una webcam-. Todas las protagonistas y participantes en el webdoc, así como la directora, son mujeres.
\end{abstract}

Palabras clave: webdoc; igualdad; mujeres; brecha salarial; Lab RTVE.

\begin{abstract}
The webdoc, as an interactive and multimedia evolution of the cinematographic and television documentary, born with the development of the Internet, keeps the same essence of its precedents: its informative and denouncing character and its critical vision of reality. This paper analyses, using the case study methodology, the webdoc En la brecha, by RTVE Lab, which was created to celebrate the International Equal Pay Day, in 2018, and through which it was intended to denounce the existing salary gap -hence the title of the webdoc- between women and men in their average annual salary. At the same time, the webdoc also aims to make visible the work of women in those sectors in which they are under-represented, through the life experience and the testimony of seven women, of different professions. The project was not limited to showing these seven cases, but
\end{abstract}




\begin{abstract}
also offered other women the possibility to participate and contribute with their own experiences and opinions through the web-recorded by themselves, with a mobile or a webcam-. All the main protagonists and participants in the webdoc, as well as the director, are women.
\end{abstract}

Key words: webdoc; equality; women; salary gap; Lab RTVE.

\title{
1. INTRODUCCIÓN
}

El documental es un género de denuncia, que como resalta Rabiger (1989) pretende mostrar a la sociedad sus fallos y que los espectadores lleguen a conclusiones críticas acerca de ella. De ahí que pueda ser considerado en la mente del público como un género "problemático», opuesto en su planteamiento al "cine de esparcimiento y evasión", pues lo que hace es concentrarse "en la ambigüedad de la vida, tal como es realmente» (Rabiger, 1989, pp. 4-5). El webdoc, como herencia digital de los documentales cinematográficos y televisivos tradicionales, también mantiene esa misma esencia, ese mismo propósito de denuncia y de crítica social, pero con el elemento añadido de la interactividad, la hipertextualidad, la multimedialidad y la posibilidad de la participación del público, lo que contribuye a enriquecer el discurso y a amplificar su difusión. Como señala Nash (2012) al analizar el lugar que ocupa el webdoc en la tradición documental y el vínculo con el formato cinematográfico y televisivo «in spite of this family resemblance, however, the webdoc challenges current thinking about documentary representation» (p. 195). A ello debe sumarse la posibilidad de la transmedialidad, de la transmisión de diferentes mensajes sobre un contenido, a través de distintos canales y plataformas (Reno, 2013, p. 207), de manera que «el relato pueda comenzar en un medio y continuar en otros» (Scolari, 2011). El webdoc puede definirse, de manera resumida, como un documental interactivo, que se difunde a través de Internet, y que se vale de todas las posibilidades del entorno digital y de la web 2.0. El webdoc, como relato interactivo, no ofrece una estructura de visionado lineal como ocurre el formato tradicional, sino que permite que sea el espectador el que de manera individual decida el orden en el que accede a los distintos contenidos que en conjunto componen la obra. Incluso puede optar libremente por consumir solo unos determinados fragmentos del relato y descartar el resto. O comenzar por lo que aparece en último lugar y acabar por los del inicio. Sigue, en parte, un planteamiento similar al de la novela 'Rayuela', de Julio Cortázar -utilizada habitualmente para hacer alusión al hipertexto-, donde los lectores podían elegir entre dos posibles órdenes de lectura, la tradicional, u otra alternativa donde el lector iba saltando de un capítulo a otro, sin mantener el orden de página, sino siguiendo el número de capítulo que el autor le iba indicando. En el caso del webdoc se da un paso más allá, pues este orden propuesto también desaparece y se ofrece al espectador un recorrido totalmente libre. Cuando Selles (2008) señala que «el documentalista, mediante la selección y puesta en escena organiza y visibiliza el material de la realidad social» (p. 8) lo hace pensando en el documental tradicional, bajo las pautas clásicas de visionado. En el caso del webdoc nos enfrentamos al reto de mostrar la realidad y aportar los diferentes puntos de vista, con una puesta en escena distinta, fragmentada, y sin una linealidad establecida en el discurso. En este sentido, puede interpretarse que el público -al tener que tomar decisiones sobre el orden del visionado- comparte con el creador de la obra la autoría del relato final: 
"La introducción de las variables de la interacción y la participación a la hora de construir el relato que contempla el documental interactivo posibilita ahora al usuario convertirse en autor, pues estará ante un relato que ya no presenta un único camino de lectura sino varios, de tal manera que podrá configurar su propio discurso alterando un orden e incluso llegando a modificarlo» (Rodríguez Fidalgo \& Sánchez Mera, 2014, p. 82).

El webdoc es la evolución digital de un formato audiovisual ya de por sí complejo por la dificultad en la delimitación entre géneros, especialmente en el caso de la televisión, donde las fronteras son más difusas, al mantener similitudes con otros formatos informativos, como el reportaje -que tiene precisamente su origen en los noticiarios cinematográficos (Barroso, 2009)-. En ese mismo sentido, como apunta Gifreu (2014a) en relación con los webdocs, "las posibilidades de creación son prácticamente infinitas, las fronteras están por delimitar y los límites por explorar y descubrir» (p. 61). Nos encontramos ante una "nueva forma de comunicación" (Gifreu, 2014a, p. 62) que aún se encuentra en fase de crecimiento y experimentación y que tiene múltiples posibilidades de desarrollo. Gifreu (2013) detecta cuatro fases diferenciadas en el desarrollo del webdoc. En primer lugar, el autor sitúa los orígenes del documental interactivo en la década de los 80-90, con su nacimiento "fuera de línea", en soporte físico (discos). En la década de 1990-2000 arranca una segunda fase, de «emergencia y experimentación» a través de diferentes soportes, y que está -como destaca Gifreu (2013, pp. 217218, a partir de Rivas, 2000)- fuertemente vinculada con la difusión cultural. De 2000 a 2010 se desarrolla una tercera fase de "constitución y consolidación» durante la cual se amplían sus soportes de exhibición, y a partir de 2010 comienza una nueva etapa caracterizada por la "diversificación» y "posible institucionalización» del género (Gifreu, 2013, p. 191). El webdoc, en su versión interactiva, accesible a través de Internet, tal y como se conoce hoy día, comienza a desarrollarse, por tanto, a partir de la década del 2000, coincidiendo con la consolidación del uso de Internet entre los usuarios, el aumento del ancho de banda y la irrupción de la denominada web 2.0. Entre los documentales pioneros en España Gifreu (2014b) destaca Guernica, pintura de guerra (2007) y Los niños que nunca volvieron (2008).

Para el mundo del periodismo y del ciberperiodismo, el desarrollo de este formato ofrece, como apuntan Vazquez-Herrero, Negreira-Rey y Pereira-Fariña (2017) «un nuevo camino para explorar la renovación de sus narrativas con un valor añadido a la oferta informativa» (p. 411). Debido a su carácter innovador y al propio reto que supone su creación, el documental es un formato objeto de atención y desarrollo por parte los denominados laboratorios de innovación de los medios, más conocidos como labs o medialabs. Como explica Salaverría (2015) se trata de «unidades de I+D+i impulsadas por los medios para innovar en tecnologías y formatos editoriales» (p. 398). Los labs trabajan en la investigación, experimentación, desarrollo e implementación de todas las nuevas innovaciones tecnológicas, lo que les permite adaptarse con más rapidez a los vertiginosos cambios que se van produciendo en el mundo del periodismo y los medios de comunicación. Un ejemplo lo encontramos en el Lab RTVE, cuyos webdocs han sido objeto de investigación por parte de diferentes autores, caso de Las Sinsombrero (Rodríguez Fidalgo, Paíno Ambrosio \& Jiménez Iglesias, 2016), Cromosoma cinco (Barrientos, 2017; De la Torre, 2017), o de un compendio de varios de sus webdocs (Rodríguez Fidalgo \& Molpeceres Arnáiz, 2013; Gifreu \& Moreno, 2014).

Las primeras incursiones de RTVE en el formato webdoc, a partir del desarrollo del Lab, son fruto de colaboraciones con productoras como Barret Films (que también participa en el webdoc En la brecha), como ocurre en el caso del proyecto Las voces 
de la memoria (RTVE, 2012a; 2012b). Como recoge Gifreu (2014c) de una intervención de Charo Marcos, del Lab RTVE, en el evento Docs21, son tres las vías que se emplean en el Lab para el desarrollo de webdocs: "la producción propia", las "colaboraciones con grandes programas de reportajes de la propia televisión" y la "coproducción externa». En el año 2016, además, el Lab RTVE presentó la iniciativa "Factoría de Webdocs», que nacía precisamente con el fin de "coproducir documentales interactivos" (RTVE, 2016a). Fue precisamente la coproducción la opción empleada en el caso del proyecto Las Sinsombrero (RTVE, 2015a) que tiene además la particularidad de que entronca con el tema del presente trabajo, pues se trata de un documental interactivo transmedia que tienen como objetivo, al igual que En la brecha (2018a), la visibilización del trabajo de la mujer y la lucha por la igualdad. Con el webdoc de Las Sinsombrero se pretende recuperar la memoria de las mujeres de la Generación del 27, las cuales se encontraban en el olvido. El Lab RTVE ha emprendido otros proyectos en esta misma dirección, aunque no específicamente bajo el formato de webdoc. Así, puede citarse el proyecto de periodismo inmersivo Vive Río (RTVE, 2016b), desarrollado para los Juegos Olímpicos de Río y que tenía entre sus objetivos el de dar visibilidad a las mujeres deportistas.

Entre los proyectos de webdoc puestos en marcha desde el Lab de RTVE pueden destacarse Haití, sobrevivir al terremoto; Cromosoma Cinco; Estafeta, 1; Historias en el retrovisor; En el reino del plomo; 50 años de la muerte de JFK: Sombras de un magnicidio; Fracking, la fiebre del gas; Sexo, maracas y chibuabuas; Que tiemble el Camino. Ponte en la piel de una persona con párkinson; Guerra a la mentira; Bugarach: ¿Cómo sobrevivir al apocalipsis maya?; Memoria de futuro o Lo que bicimos fue secreto, entre otros (RTVE, 2019a).

Respecto al uso del webdoc como herramienta de denuncia y de participación ciudadana, Ortuño Mengual y Villaplana Ruiz (2017) aluden al concepto de «activismo transmedia" y de "narrativas de participación para el cambio social» y ponen como ejemplo el 'Proyecto Quipu', que consiste en una plataforma webdoc basada en la recopilación de testimonios orales (pp. 136-137). El webdoc En la brecha apunta en esta misma dirección, al tener como propósito la lucha por la igualdad a partir de la denuncia de la brecha salarial y de la visibilización del trabajo de la mujer en sectores tradicionalmente masculinizados y donde la mujer está infrarrepresentada.

El Lab de RTVE ha desarrollado ya, por tanto, diferentes proyectos de innovación periodística bajo esta misma perspectiva feminista, en la búsqueda de igualdad real entre mujeres y hombres -Las Sinsombrero, Vive Río, y el caso objeto de análisis, En la brecha-. En este sentido, la propia Ley 17/2006, de 5 de junio, de la radio y la televisión de titularidad estatal (BOE, 2006) establece que entre las funciones que la Corporación RTVE tiene encomendada se encuentra la de "fomentar la protección y salvaguarda de la igualdad entre hombre y mujer, evitando toda discriminación entre ellos» (art. 3, punto $2 \mathrm{k}$ ), por lo que la difusión de este tipo de contenidos forma parte de su labor como servicio público.

En este sentido, debe recordarse, por otra parte, que el género documental en su formato tradicional -cinematográfico y televisivo-, no han sido ajeno a la situación de la mujer y la ha convertido en protagonista de documentales en los cuales se visibilizan o denuncian diferentes problemáticas y circunstancias. Muchos de estos trabajos son realizados por parte de mujeres documentalistas. Así, podemos citar, como ejemplos, Surname Viet Given Name Nam (1989), de ITrinh T. Minh-ha (Gifrau, 2013, p. 115); Réponse de femmes (1975), de Agnès Varda (IMDb, 2019a), Yo, tú, Ismaelina 
(1981), del Grupo Feminista Miércoles (Azuaga, 2003, p. 370); No les pedimos un viaje a la luna (1986), de Mari Carmen de Lara (Torres San Martín, 2003, p. 391); Las Madres: The Mothers of the Plaza de Mayo (1986) y Señorita extraviada (2001), de Lourdes Portillo (2001); El toro por las astas (2006) y Ella se lo buscó (2012), de Susana Nieri (Chaher, 2012); Miss Representation (2011) de Jennifer Siebel Newsom (IMDb, 2019b) o Sonita (2015), de Rokhsareh Ghaemmaghami (IMDb, 2019c). Entre las obras sobre la situación de las mujeres dirigidas por hombres documentalistas pueden citarse, igualmente, La maleta de Marta (2013), de Günter Schwaiger (RTVE, 2014); La guerra contra las mujeres (2013), de Hernán Zin, (RTVE, 2015b); It’s a girl (2012), de Evan Grae Davis o Girl Rising (2013), de Richard Robbins. En relación con TVE puede mencionarse a la directora Isabel Coixet, autora del documental La mujer, cosa de hombres (2009), emitido dentro de la serie Cincuenta años de..., en el que utilizó imágenes de archivo de RTVE, vinculando el papel que tradicionalmente se ha asignado a la mujer en la sociedad, y la imagen que se ha transmitido de ella a través de los medios de comunicación, con el problema de la violencia de género (RTVE, 2009).

El webdoc de temática feminista recibe, por tanto, la herencia y la retroalimentación de los documentales cinematográfico y televisivo tradicionales, aprovechando las ventajas de la interactividad del formato digital. Entre los webdocs de denuncia en torno a la situación de la mujer puede destacarse, por su carácter pionero, La cité des mortes, sobre Ciudad Juárez (2005), desarrollado por la productora digital Upian (Lacitedesmortes.net, 2005). También debe resaltarse el webdoc y proyecto transmedia Mujeres en venta (2015), que combina diferentes recursos como mapas interactivos, comics, fotografías, documental para TV, libros, etc., y que ha sido merecedor de distintos premios (Documedia, 2015).

\section{OBjetivos}

El objetivo de este trabajo es el de analizar el webdoc En la brecha (2018) del Lab RTVE, como espacio de información y de denuncia de la brecha salarial entre mujeres y hombres y de visibilización del trabajo de la mujer en sectores tradicionalmente masculinizados y donde su presencia es menor. De manera específica, se persiguen los siguientes objetivos:

- Analizar cuáles son las diferencias en la relación entre emisor y receptores en el formato de webdoc frente al documental tradicional, qué cambios se producen en el papel de ambos gracias a la interactividad y a la posibilidad de participación, y qué ventajas puede tener el webdoc frente al documental tradicional.

- Evaluar de qué forma el webdoc actúa como instrumento de información, denuncia, concienciación y crítica social.

- Examinar, de manera particular, de qué manera En la brecha contribuye a visibilizar el problema de la brecha salarial y pone en valor el trabajo de las mujeres en sectores donde aún se encuentran infrarrepresentadas.

- Analizar el webdoc En la brecha atendiendo al contexto, estructura básica, narrativa, protagonistas, lenguaje, estética y diseño, mensaje y temáticas abordadas, recursos multimedia, interacción con la audiencia y participación. 


\section{Metodología}

La metodología empleada en este trabajo es de corte cualitativo y se basa en el estudio de caso como técnica de investigación. El trabajo se fundamenta en el análisis del contenido y del diseño del webdoc En la brecha, así como al estudio de la interactividad y la participación del público, y la revisión documental de las informaciones publicadas en la Red en torno a dicha obra. Para ello se procede a la consulta de cada uno de los diferentes apartados en los que se estructura el webdoc y la visualización y análisis en profundidad de todos los contenidos que lo componen, tanto los que constituyen el núcleo del trabajo, como las aportaciones realizadas por cada una de las participantes. Asimismo, se procede a la búsqueda y análisis de las informaciones publicadas en relación con proyecto, tanto en la propia web de RTVE como en otros medios de comunicación.

Los elementos objeto de análisis son los indicados en el apartado de objetivos: contexto, estructura básica, narrativa, protagonistas, lenguaje, estética y diseño, mensaje y temáticas abordadas, recursos multimedia, interacción con la audiencia y participación.

\section{Resultados}

Con motivo de la celebración del Día Internacional por la Igualdad Salarial, el 22 de febrero de 2018 (en una fecha muy cercana, además, a la conmemoración del Día Internacional de la Mujer Trabajadora, el día 8 de marzo) el Lab de RTVE lanzó, a través de Playz, un webdoc titulado En la brecha. El proyecto se inscribe en un contexto de renacimiento del movimiento feminista, tanto a nivel internacional (a través del movimiento \#MeToo) como en España, donde la huelga feminista del 8 de marzo de 2018 y las manifestaciones que se desarrollaron durante ese día tuvieron un enorme seguimiento en todo el país, llegando incluso a convertirse España en un referente internacional, al hacerse eco medios de comunicación de todo el mundo. La conmemoración del 8 de marzo de 2019 ha tenido similar nivel de acogida y ha servido para visibilizar la fuerza del movimiento feminista en la lucha por la igualdad real entre mujeres y hombres.

El webdoc En la brecha nace en este contexto, y está centrado, específicamente, en el ámbito laboral. Como recoge la propia web de RTVE, el objetivo fundamental de este proyecto era el de "reflexionar sobre las desigualdades de género en el trabajo" (RTVE, 2018b). En la brecha retrataba "el día a día de siete mujeres que trabajan en ámbitos tradicionalmente masculinizados»-según los propios términos utilizados por RTVE-, y a su vez, ofrecía a los usuarios la posibilidad de «dejar sus testimonios en vídeo sobre sus experiencias» (RTVE, 2018b).

El webdoc, además de estar disponible en la web del Lab y de Playz, de RTVE, también ha sido emitido por televisión, en el espacio Documentos TV de La 2 -bajo el formato de documental televisivo, con una estructura lineal-, el día 5 de marzo de 2019, como parte de la programación especial con motivo de la celebración, el 8 de marzo, del Día Internacional de la Mujer Trabajadora (RTVE, 2019b). Este documental tenía una duración de 55:37 minutos y fue montado a partir de las imágenes del webdoc. Estamos, por tanto, ante un documental interactivo cuyo contenido se difunde a través de dos canales: Internet y televisión, con lo que pasa de ser un 
documental exclusivamente digital para ser también un documental televisivo, compartiendo material audiovisual, pero con una estructura diferenciada, al adquirir, en el caso del formato televisivo, una estructura lineal. Nos encontramos ante un formato a medio camino entre el crossmedia y el transmedia, ya que el resultado es distinto, aunque el relato se construya con el mismo contenido.

Como también se detalla a través de la web de RTVE (2018b), y de los créditos de En la brecha (RTVE, 2018a), el proyecto estaba impulsado por el Lab de RTVE, y producido por Barret Films, además de contar con el apoyo de la Diputación de Valencia. El webdoc está dirigido por una mujer, Claudia Reig, que también aporta su propio testimonio, como directora de documentales, en uno de los vídeos.

El webdoc arranca con una portada que incluye un vídeo de presentación en el que se muestra a las protagonistas. Tiene una duración de 1 minuto y 26 segundos y en él se recogen declaraciones con algunas de las principales ideas que se abordan en el webdoc, a la vez que se promueve la participación. La portada cuenta con un botón, en la esquina superior izquierda que nos permite poder saltar la presentación. Una vez en la pantalla principal encontramos siete tiras fotográficas con los rostros de las protagonistas. Al pulsar sobre cualquiera de ellas, accedemos a cada una de las historias. De cada protagonista se nos ofrecen tres opciones: "Agenda", "Perfil»y "Testimonio". Junto a la fotografía del testimonio (en la esquina inferior izquierda) se ubica un botón circular que nos permite acceder a "Otras historias" y también participar. En la parte superior derecha se nos ofrece otro botón circular con el título «Cómo navegar en la web" y debajo se incluyen los iconos de Twitter y Facebook para compartir los contenidos. En el pie de página podemos acceder a los Créditos, el Aviso Legal, el Aviso de privacidad y la Política de cookies de la web. En el centro se encuentra la "Agenda", eje en torno al que gira el webdoc y, sobre la que hablaremos posteriormente. La estructura de la web es, por tanto, bastante sencilla y muy intuitiva, por lo que resulta fácilmente accesible a cualquier usuario.

En cuanto a la estructura básica, el webdoc se organiza en torno a siete mujeres -las protagonistas del documental- y sus propias historias y vivencias personales. Se trata, concretamente, de una entrenadora de fútbol, una estibadora, una técnica de sonido, una chef, una mecánica de automoción, la CEO de un equipo de eSport y una cirujana. De cada una de ellas podemos conocer su "Perfil» y sus aspiraciones, a través de una breve presentación biográfica en formato textual y apoyada con fotografías con efecto zoom out. Son, en concreto:

- Patrícia, entrenadora de fútbol femenino y expilota de reactor de la Armada Española (fue la primera mujer que lo consiguió). Estudió Comunicación Audiovisual, pero se hizo piloto, y posteriormente, entrenadora de fútbol. Se considera una mujer rebelde. Trabaja en un proyecto personal de cooperación en Uganda llamado 'Goals for Freedom', en el que a través del fútbol intenta "transmitir valores a niños, niñas y mujeres con sida" (RTVE, 2018a) para que ganen en confianza, liderazgo y comunicación.

- Natalia, estibadora del puerto de Valencia. Consiguió todos los carnés necesarios para ello y superó todas las pruebas. Para ella, es un trabajo muy gratificante, "que requiere un equilibrio entre esfuerzo intelectual y físico» (RTVE, 2018a). Trabaja en igualdad con sus compañeros. En el momento de la grabación del webdoc se planteaba formarse en "la trinca", trabajo que "consiste en poner los anclajes de los contenedores al barco» (RTVE, 2018a). 
- Laura, técnica de sonido, música y DJ. Comenzó a tocar la guitarra a los 18 años, después pasó a tocar en grupos y componer sus propias canciones, y acabó estudiando un Ciclo Formativo de Sonido. En su trabajo se encarga del control de la mesa de mezclas. Como próximos proyectos futuros tiene los de crear un colectivo de sonidistas y luchar, como feminista, contra los estereotipos y la discriminación a través de talleres de sensibilización en colegios.

- Rakel, chef y propietaria de un restaurante. Estudió Cocina en una escuela y al acabar, con 21 años, montó su propio restaurante. Reconoce que ha trabajado muy duro y sacrificado muchas cosas por su proyecto. En 2017 participó en el concurso Top Chef y lo ganó.

- Yadira, mecánica de automoción. De pequeña practicó kárate y jugó al fútbol. Siempre le gustó abrir aparatos y reparar cosas. Estudió un Ciclo Medio de Electromecánica y después un Ciclo Superior de Automoción. Recuerda que en su clase solo había tres chicas. Trabaja en la ITV (Inspección Técnica de Vehículos) como inspectora mecánica y también es comisaria técnica en la Federación de Automovilismo, donde se encarga de hacer revisiones a los karts que compiten en las pruebas.

- Yara, CEO de un equipo de eSport. Desde muy joven estuvo vinculada al deporte, practicando escalada, montañismo, y siendo jugadora profesional de balonmano con el equipo de su colegio. Estudió Publicidad y Relaciones Públicas y Periodismo, y ejerció durante varios años como periodista deportiva. Posteriormente realizó un máster de gestión deportiva y estuvo desarrollando su profesión en una residencia de alto rendimiento, donde hizo su primer contacto con los eSports, ámbito en el que trabaja actualmente.

- Esther, cirujana general y del aparato digestivo en el Hospital General de Granollers. Tuvo claro desde niña que quería dedicarse a la medicina y fue esa la carrera que estudió. También ha formado una familia. Tiene tres hijos, y reconoce que, si no repartiera las tareas con su marido, sería imposible poder hacer frente a todo. Su principal hobby es el de correr.

A través del espacio "Agenda» -el cual imita un cuaderno o un libro abierto, mostrando dos páginas contrapuestas-, podemos acceder a los enlaces (que pueden ser textos o fotografías) con los vídeos de las protagonistas. A través de estos vídeos, -entre seis y ocho por cada una de las protagonistas- y de entre uno y dos minutos de duración, aproximadamente, cada uno, se muestran diferentes momentos de su día a día (profesión, vida familiar, aficiones...), pequeños fragmentos de las distintas partes de la vida de las protagonistas. Esta agenda -que indica, por ejemplo, fechas y horas de las actividades de cada mujer-, marca, indirectamente, una pauta temporal en el orden de visualización de los vídeos (aunque no sea la pretensión de un webdoc la de establecer de qué manera o siguiendo qué orden deben visualizarse los contenidos). Cada una de las protagonistas tiene una agenda con un diseño diferenciado, un acierto desde el punto de vista estético y estilístico, ya que permite distinguir más fácilmente a cada una de las mujeres y conocerlas mejor, a través de las imágenes y dibujos que acompañan a las anotaciones de su agenda. Cada vez que situamos el ratón sobre alguno de los enlaces se activa un vídeo en bucle, con un fondo semitransparente -a modo de previsualización-, con los primeros frames de dicho vídeo, para poner en antecedentes al espectador sobre el contenido de ese fragmento.

En tercer lugar, cada historia personal se acompaña de una declaración de la protagonista, grabada en plano corto sobre un fondo negro. Estos testimonios se 
estructuran en torno a siete ejes temáticos: «micromachismos», «liderazgo», «barreras», "maternidad", "acoso", "Salario" y "referentes». Los siete bloques sirven de guía a las usuarias a la hora de participar en el documental ofreciendo su testimonio, ya que el planteamiento de este proyecto es que el webdoc no solo se componga de las siete historias iniciales, sino también en las aportaciones y reflexiones de otras mujeres a partir de la visualización de la obra. Lo que se persigue es que el documental no solo sea resultado del trabajo de una directora y su equipo, sino también de las propias consumidoras, que adquieren de esta forma el papel de prosumidoras (la suma de consumidora + productora). Así, como se explica en la web acerca de las siete protagonistas,

"Sus experiencias son solo el inicio de una conversación abierta a la participación de todas las mujeres, de cualquier ámbito profesional a través de la plataforma de 'crowdsourcing', una interfaz a través de la cual cualquier usuaria puede grabar y subir un vídeo-testimonio.

[...] Este es, por tanto, un proyecto de creación colectiva donde las espectadoras son las creadoras. El documental quiere ejercer de altavoz para que se escuchen todas las voces, haciendo visibles los problemas que sufren las mujeres en el ámbito laboral, simplemente por el hecho de ser mujeres trabajadoras.» (RTVE, 2018b).

Nos encontramos por tanto ante un webdoc no solo interactivo por el hecho de que el público puede decidir libremente el orden y la forma en la que accede a los contenidos, sino también por la vía que abre a la participación, por medio del espacio "¿Y tú?» a través del cual las usuarias pueden enviar vídeos, grabados con su propio móvil o webcam, para que formen parte del propio webdoc. De ahí que estemos, como se afirma en la web de RTVE ante «un proyecto de creación colectiva», donde, tal como se destacaba antes, la autoría no es solo de los creadores del webdoc, sino también de las personas que interactúan y participan en él, lo que hace que estemos ante una autoría compartida. Lo que se persigue a través de la propuesta de En la brecha es una "puesta en común de experiencias" que permitan "ayudar a romper el aislamiento y el espejismo de excepcionalidad" en el que se encuentran muchas mujeres por trabajar en sectores donde su presencia aún es minoritaria, las barreras y las dificultades a las que se enfrentan en su trabajo o el problema del machismo (RTVE, 2018). En la brecha es planteado, así como "una conversación abierta» en la que "las usuarias pueden compartir también estrategias para luchar contra la discriminación y sus éxitos para conseguir la plena integridad" (RTVE, 2018). En resumen, persigue dar voz a las mujeres y empoderarlas en una sociedad donde aún no se alcanzado una igualdad real, y donde existen brechas y discriminaciones en los distintos ámbitos de la vida.

Por otra parte, para facilitar el acceso a los contenidos el webdoc incluye como se ha mencionado anteriormente un botón titulado "¿Cómo navegar la web?», a modo de FAQ o manual de instrucciones que pueden consultar todas aquellas personas que tengan alguna duda sobre sobre la forma en la que debe ser visualizado el documental interactivo. Asimismo, se ofrece la posibilidad de compartir el enlace a cada uno de los contenidos del webdoc a través de Twitter y Facebook, bajo el hashtag \#EnLaBrecha.

Respecto al tipo de contenidos multimedia utilizados en el webdoc debe destacarse la combinación de texto, música, vídeo, fotografías y animaciones. De manera particular debe resaltarse el uso de dos elementos: las fotografías, en plano corto, de 
cada una de las protagonistas y sus agendas, que a su vez se convierten en el espacio para la visualización de los vídeos.

Una de las principales particularidades de este documental es que tiene como protagonistas a las mujeres. Aunque aparezcan hombres en las imágenes de la vida diaria de las siete protagonistas, no hablan directamente a cámara ni tienen un papel principal. Las que ofrecen los testimonios son las mujeres. Lo mismo ocurre en el caso de las aportaciones de las mujeres que aceptan la propuesta del webdoc de participar en él contando sus propias experiencias, vivencias y opiniones.

En total, junto a las agendas y testimonios de las siete protagonistas, se ofrecen, por parte de las otras mujeres participantes, 9 testimonios sobre salarios, 5 sobre liderazgo y autoridad, 16 sobre barreras y techos de cristal, 11 sobre acoso, 14 sobre maternidad y conciliación, 10 sobre referentes para otras mujeres y 18 sobre micromachismos. Se observa, por tanto, que son aquellas cuestiones relacionadas con el micromachismo, las barreras y la conciliación familiar y laboral, las que acaparan el mayor número de testimonios. Algunas de las mujeres han realizado aportaciones en más de una categoría, siempre en relación con su actividad laboral, tema en torno al que gira el webdoc.

En cuanto al perfil de las participantes, destacamos la presencia de mujeres de todas las edades, jóvenes y mayores, de diferentes profesiones (administrativas, empresarias, gestoras, abogadas, educadoras, enfermeras, artistas, escritoras, cantantes, periodistas, diseñadoras, ganaderas, vendedoras, sindicalistas, etc.), y con distintas experiencias vitales. También aluden, en algunos casos, a la doble discriminación que sufren, por su condición de mujer, y por su religión, raza o diversidad funcional.

En total, son 72 los testimonios que las usuarias han compartido, contribuyendo de esta forma en la propia creación del webdoc. A ellos hay que sumar los 7 aportados por las protagonistas. A través de todos estos comentarios de corta duración, grabados en vídeo -a través de webcam o smartphone (lo que hace que la calidad de la imagen y el sonido en algunos casos concretos sea algo deficiente)- y con una duración aproximada de uno a dos minutos, se visibiliza la situación que sufren o han sufrido muchas mujeres, sus dificultades y las barreras a las que han tenido que enfrentarse. Como explicaba la directora del webdoc, Claudia Reig, en la presentación del trabajo, su pretensión, al ofrecer la posibilidad de participar en el webdoc era la de «crear una comunidad de experiencias de mujeres, un espacio de apoyo mutuo, de visibilización y de sonoridad» (EFE, 2018). El webdoc se convierte de esta forma en un medio para que las propias mujeres, compartiendo con otras sus experiencias, se sientan apoyadas y respaldadas frente a sus problemas. Es un canal a través del que pueden tener voz y empoderarse, lo que hace de este documental interactivo una herramienta para la lucha por la igualdad y una vía para que la sociedad en su conjunto pueda tomar conciencia del problema de la desigualdad, tanto en el ámbito laboral como en el personal.

Respecto a la visualización del webdoc, es la propia audiencia la que decide a qué contenidos accede o en qué orden lo hace. El formato, como ya se había indicado, rompe con la linealidad del documental tradicional y permite que sean los usuarios los que tomen la decisión de elegir libremente el orden de visionado, aunque como ya se ha indicado anteriormente, la presencia de la agenda hace que exista una línea temporal marcada por las horas y las fechas. 


\section{Discusión DE RESUltados}

Si comparamos este webdoc o documental interactivo con el formato tradicional, la principal diferencia la encontramos en la relación entre el emisor y receptores ya que aquí el público tiene tanto la libertad de elegir el orden en el que va a acceder a los contenidos, como la posibilidad de participar en el propio webdoc, aportando el testimonio personal, como es el caso de las mujeres que participan en la obra En la brecha. Esto supone una clara ventaja con respecto al formato tradicional, puesto que el grado de implicación aquí es mayor, dado que el usuario tiene que adoptar un papel activo para poder acceder a los contenidos, o para generarlos. En este caso solo han participado mujeres, ya que la propuesta iba dirigida directamente a ellas. Pero una alternativa posible sería la de incorporar también el testimonio de hombres que quieran aportar su visión acerca de la situación de desigualdad en el mercado laboral, generando de esta forma un diálogo en torno a la igualdad real entre hombres y mujeres en la sociedad. Para alcanzar la igualdad, el papel de los hombres es tan importante como el de las mujeres. Es una lucha conjunta por conseguir una sociedad más justa.

En este sentido, como ya ha señalado en la introducción, este webdoc se enmarca en una corriente de documentales -tanto cinematográficos y televisivos, como interactivos- que se encargan de visibilizan y denunciar las situaciones de desigualdad que sufren las mujeres. En el caso del Lab RTVE, se trata de una apuesta decidida que comenzó con otros trabajos de innovación periodística como Las Sinsombrero o Vive Río.

Por otra parte, debe destacarse cómo los testimonios aportados tanto por las principales protagonistas como por las usuarias que decidieron participar en el webdoc son ricos y valiosos, y tienen una vertiente crítica y de denuncia que puede contribuir a una mayor concienciación de la ciudadanía. Pero, sobre todo, como ya se ha destacado anteriormente, destacan por su capacidad para generar comunidad y para hacer que las mujeres se sientan apoyadas y respaldadas ante las situaciones de desigualdad a las que han tenido que hacer frente a lo largo de sus vidas. Además, el propio webdoc, al poner en valor el trabajo que realizan las mujeres protagonistas en sectores donde hoy día aún están infrarrepresentadas permite que otras mujeres pueden pensar en ellos y planteárselos como una futura vía laboral, es decir, que las protagonistas puedan servir de referentes para niñas y jóvenes que tienen que elegir a qué quieren dedicarse profesionalmente.

En referencia a la estructura de En la brecha, hemos de recordar que la creación de un webdoc supone un cambio en el planteamiento acerca de quién decide el hilo de la historia. En esta modalidad de documental el creador pierde el control sobre la forma en la que va a ser consumido el contenido que ha elaborado (aunque, en cualquier caso, ha sido quien por medio de la selección y descarte de los fragmentos el que ha establecido y decidido el contenido global). Nos encontramos ante una situación similar a la que se produce en el consumo de información a través de los medios digitales, con la fragmentación y la segmentación de los contenidos, que hace que -a diferencia de los medios tradicionales, donde es el medio quien establece el orden y qué contenidos aparecen- sea el propio usuario el que decida sus temas de interés, lo que limita su conocimiento de la actualidad a aquellos contenidos sobre los que ha buscado información de una manera activa. En el caso de los webdoc esta libertad en el acceso al contenido también lleva, en cierto modo, a una situación similar. Si una de las características que define el documental es el hecho de que intente mostrar todos 
los puntos de vista sobre el tema, aportando la visión más rica posible, a través de múltiples fuentes, aquí es el espectador el que decide el nivel de profundización y las fuentes a las que quiere acceder de entre todas las que se les ofrece.

Otro aspecto que también debe ser tenido en cuenta es el perfil de audiencia de los webdoc. Si analizamos los últimos datos del EGM (AIMC, 2019) podemos comprobar que Internet es el medio más utilizado por los jóvenes. También lo es, igualmente, por las personas de hasta 54 años, ya que hasta esa edad el consumo de Internet es superior al de televisión, según la última encuesta realizada. Es solo a partir de los 55 años, cuando las personas consumen más televisión que Internet, observándose aquí la existencia de una brecha digital generacional en el acceso a la tecnología. Estos datos nos permiten comprobar que la manera más sencilla de llegar a los más jóvenes es a través del entorno digital, y que también lo es en el de la población adulta de hasta los 54 años. Tenemos, por tanto, en esa franja de edad al principal público objetivo de los webdoc, lo que no quiere decir que este tipo de contenidos no pueda ser consumido por personas de cualquier edad.

\section{Conclusiones}

El primer aspecto que debe destacarse es la importancia del documental En la brecha para visibilizar el trabajo de las mujeres en sectores donde su presencia es minoritaria, o donde están infrarrepresentadas, haciendo que puedan servir de ejemplo para otras mujeres, niñas y jóvenes que quieran emprender su carrera profesional en esa misma dirección. Por otra parte, da voz a las mujeres, empoderándolas. No solo cuenta siete historias personales, de mujeres que trabajan en sectores mayoritariamente masculinizados, sino que también recoge testimonios de otras mujeres acerca de su vida laboral, enriqueciendo la experiencia y promoviendo el intercambio de vivencias, ideas y opiniones. Podría calificarse como un ejemplo de sororidad, de apoyo y solidaridad entre mujeres. Como ya he ha indicado, se inscribe dentro de una corriente de documentales que persiguen este mismo fin, y en cuya realización participan tanto mujeres como hombres.

Por otra parte, resulta clara la necesidad de que desde el ámbito de la radio y la televisión pública se trabaje en la sensibilización y toma de conciencia de la ciudadanía acerca del problema de la desigualdad que sufren las mujeres en el ámbito laboral. En este sentido, el webdoc En la brecha puede ser un ejemplo del cumplimiento de la función social que la RTVE tiene encomendada en relación con el fomento de la igualdad. Además, el formato digital permite que pueda llegar de manera más efectiva a la población más joven, que es la gran consumidora de contenidos en la red, y que es uno de los principales públicos destinatarios de este webdoc.

Por último, debe destacarse que el webdoc, como documental interactivo, planteado para el entorno digital, también sigue ejerciendo la tradicional función de denuncia y crítica social del documental cinematográfico y televisivo, pero con el valor añadido de la interactividad y la participación. 


\section{Bibliografía}

AIMC - Asociación para la Investigación de Medios de Comunicación (2018). EGM: Febrero a noviembre 2018. RESUMEN General. AIMC. Recuperado de https://www.aimc.es/a1mcc0nt3nt/uploads/2018/11/resumegm318.pdf

Azuaga, R. (2003). Yo, tu, Ismaelina. En Paranaguá, P. A. (Ed.). Cine Documental en América Latina (pp. 370-372). Madrid: Cátedra.

Barrientos-Bueno, M. (2017). El webdoc, un formato multimodal en el entorno televisivo digital multipantalla. El caso de Cromosoma Cinco. Revista Signa, 26, 893-906. doi: https://doi. org/10.5944/signa.vol26.2017.19928

Barroso, J. (2009). Realización de documentales y reportajes. Madrid: Síntesis.

Cortázar, J. (1993). Rayuela. Barcelona: RBA Editores.

BOE (2006). Ley 17/2006, de 5 de junio, de la radio y la televisión de titularidad estatal. $B O E$ (Boletín Oficial del Estado), 134, 21027-21218. Recuperado de https://www.boe.es/buscar/ act.php?id=BOE-A-2006-9958

Chaher, S. (2012). Ella se lo buscó. Comunicación para la igualdad. Recuperado de http://comunicarigualdad.com.ar/ella-se-lo-busco/

De la Torre Espinosa, M. (2017). Estrategias transmediales y autoficcionales en Cromosoma 5 , de María Ripoll y Lisa Pram. En Marcos Ramos, M. (Ed.). Historia, literatura y arte en el cine en español y portugués. Estudios y perspectivas (pp. 934-944). Salamanca: Centro de Estudios Brasileños. Recuperado de http://www.cebusal.es/download/libro-cihalcep-web-ok.pdf

Documedia (2015). Mujeres en venta. Recuperado de http://www.documedia.com.ar/mujeres/

EFE (2018). El documental 'En la Brecha' da voz a 7 mujeres que hablan sobre desigualdad laboral. EFE. Recuperado de https://www.efe.com/efe/comunitat-valenciana/sociedad/ el-documental-en-la-brecha-da-voz-a-7-mujeres-que-hablan-sobre-desigualdad-labo$\mathrm{ral} / 50000880-3529746$

Grae Davis, E. (2019). Evan Grae Davis. Recuperado de http://evangraedavis.com/

Gifreu, A. (2013). El documental interactivo como nuevo género audiovisual. Estudio de la aparición del nuevo género, aproximación a su definición y propuesta de taxonomía y de modelo de análisis a efectos de evaluación, diseño y producción (Tesis Doctoral). Universidad Pompeu Fabra, Barcelona. Recuperada de http://agifreu.com/interactive_documentary/ TesisArnauGifreu2012.pdf

Gifreu, A. (2014a). Evaluación del estado del arte en relación con la temática, las plataformas y la experiencia del usuario. Telos (Cuadernos de Comunicación e Innovación), 96, 60-71. Recuperado de https://telos.fundaciontelefonica.com/archivo/numero096/evaluacion-delestado-del-arte-en-relacion-con-la-tematica-las-plataformas-y-la-experiencia-del-usuario/

Gifreu, A. (2014b). Breve historia III (Consolidación, 2000-2010). España: Blog Lab RTVE. Recuperado de https://blog.rtve.es/webdocs/2014/02/breve-historia-iiiconsolidaci\%C3\%B3n-2000-2010.html

Gifreu, A (2014c). Crónica desde el Docs 21 Físico - 2a parte, tarde. España: Blog Lab RTVE. Recuperado de https://blog.rtve.es/webdocs/2014/06/cr\%C3\%B3nica-desde-el-docs21-f\%C3\%ADsico-2a-parte-tarde.html

Gifreu, A. \& Moreno, V. (2014). Estrategias y modelos de financiación del documental interactivo y transmedia. Fonseca, Journal of Communication, 9, 41-63. Recuperado de http://revistas. usal.es/index.php/2172-9077/article/view/12241/12591

Girl Rising (2019). Girl Rising. Recuperado de https://girlrising.org/

IMDb (2019a). Réponse de femmes. IMDb. Recuperado de: https://www.imdb.com/title/ tt0073619/

IMDb (2019b). Miss Representation. IMDb. Recuperado de https://www.imdb.com/title/ tt1784538/?ref_=nm_ov_bio_lk1

IMDb (2019c). Sonita. IMDb. Recuperado de https://www.imdb.com/title/ tt5278928/?ref_=nm_flmg_dr_1 
Lacitedesmortes.net (2005). La cité des mortes. Upian. Recuperado de http://www.lacitedesmortes.net/

Nash, K. (2012). Modes of interactivity: analysing the webdoc. Media Culture \& Society, 34 (2), $195-210$.

Portillo, L. (2001). The films and videos of Lourdes Portillo. Señorita Extraviada. Recuperado de http://www.lourdesportillo.com/films/films_senorita.php

Rabiger, M. (1989): Dirección de documentales. Madrid: Instituto Oficial de Radio y Televisión RTVE

Reno, D. (2013). Interfaces e linguagens para o documentário transmídia. Fonseca, Journal of Communication, 6 (2), 204-225. Recuperado de http://revistas.usal.es/index.php/2172-9077/ article/view/12093/12452

Rodríguez Fidalgo, M. I. \& Molpeceres Arnáiz, S. (2013). Los nuevos documentales multimedia interactivos: construcción discursiva de la realidad orientada al receptor activo. Historia y Comunicación Social, 18 (Esp.), 249-262, doi: http://dx.doi.org/10.5209/rev_HICS.2013. v18.44325

Rodríguez Fidalgo, M. I. \& Sánchez Mera, A. (2014). La interactividad, hipertextualidad y la multimedialidad al servicio del género documental. Estudio de caso del webdoc 'En el reino del plomo' de Rtve.es. En León, B. (Coord.) Nuevas miradas al documental. Salamanca: Comunicación Social, Ediciones y publicaciones, pp. 82-94.

Rodríguez Fidalgo, M. I., Paíno Ambrosio, A. \& Jiménez Iglesias, L. (2016). El soporte multiplataforma como clave de éxito de la Narración Transmedia. Estudio de caso del webdoc 'Las Sinsombrero'. Icono 14, 14 (2), 304-328, doi: https://doi.org/10.7195/ri14.v14i2.967

RTVE (2009). 50 años de... - La mujer, cosa de hombres (Isabel Coixet). España: RTVE. Recuperado de http://www.rtve.es/alacarta/videos/50-anos-de/50-anos-mujer-cosa-hombresisabel-coixet/5128059/

RTVE (2012a). Documentos TV. Las voces de la memoria. España: RTVE. Recuperado de http:// www.rtve.es/television/20120918/documentos-tv-voces-memoria/462792.shtml

RTVE (2012b). Las voces de la memoria. España: Barret Films \& AFAV. Recuperado de http:// vocesdelamemoria.rtve.es/

RTVE (2014). El documental - La maleta de Marta. España: RTVE. Recuperado de http://www. rtve.es/alacarta/videos/el-documental/documental-maleta-marta/2168287/

RTVE (2015a). Las Sinsombrero. España: RTVE, INTROPÍAmedia \& yolaperdono. Recuperado de http://www.rtve.es/lassinsombrero/

RTVE (2015b). Documentos TV. 'La guerra contra las mujeres'. España: RTVE. Recuperado de http://www.rtve.es/television/20150817/documentos-tv-guerra-contra-mujeres/802860. shtml

RTVE (2016a). El Lab de RTVE.es presenta Factoría de Webdocs, una iniciativa para coproducir documentales interactivos. España: RTVE. Recuperado de http://www.rtve.es/ rtve/20161212/lab-rtvees-presenta-factoria-webdocs-iniciativa-para-coproducir-documentales-interactivos/1453200.shtml

RTVE (2016b). Vive Río. España: RTVE \& Inmediastudio Comunicación. Recuperado de http:// lab.rtve.es/rio-2016/vive-rio-vr/

RTVE (2018a). En la brecha. España: RTVE \& Barret Cooperativa Valenciana. Recuperado de http://lab.rtve.es/webdocs/brecha/

RTVE (2018b). 'En la brecha', el webdoc que reflexiona sobre las desigualdades de género en el trabajo. España: RTVE. Recuperado de http://www.rtve.es/playz/20180220/brecha-webdocreflexiona-sobre-desigualdades-genero-trabajo/1681307.shtml

RTVE (2019a). Webdocs. Lab RTVE. España: RTVE. Recuperado de http://www.rtve.es/lab/ webdocs/

RTVE (2019b). Documentos TV - En la brecha. España: RTVE. Recuperado de http://www.rtve. es/alacarta/videos/documentos-tv/documentos-tv-brecha/5036458/

Salaverría, R. (2015). Los Labs como fórmula de innovación en los medios. El Profesional de la Información, 24 (4), 397-404, doi: https://doi.org/10.3145/epi.2015.jul.06 
Scolari, C. A. (2011). Transmedia storytelling: más allá de la ficción. Recuperado de https:// hipermediaciones.com/2011/04/10/transmedia-storytelling-mas-alla-de-la-ficcion/

Sellés, M. (2008): El documental. Barcelona: UOC.

Torres San Martín, P. (2003). No les pedimos un viaje a la luna. En Paranaguá, P. A. (Ed.). Cine Documental en América Latina (pp. 391-393). Madrid: Cátedra.

Vázquez-Herrero, J.; Negreira-Rey, M.-C. \& Pereira-Fariña, X. (2017). Contribuciones del documental interactivo a la renovación de las narrativas periodísticas: realidades y desafíos. Revista Latina de Comunicación Social, 72, 397-414, doi: 10.4185/RLCS-2017-1171 
